\title{
To Disclose or Not to Disclose? Reasons for HIV Serostatus Disclosure and Non-disclosure by People Living with HIV/AIDS in Eastern India
} Sangeeta Kansal ${ }^{1}$, Madhutandra Sarkar ${ }^{2}$, Alok Kumar ${ }^{3}$, Jaya Chakravarty ${ }^{4}$, Rakesh Kumar ${ }^{5}$

${ }^{1}$ Professor, Department of Community Medicine, Institute of Medical Sciences, Banaras Hindu University, Varanasi, Uttar Pradesh, India; ${ }^{2}$ Medical Officer, Department of Community Medicine, Institute of Medical Sciences, Banaras Hindu University, Varanasi, Uttar Pradesh, India; ${ }^{3}$ Associate Professor, Department of Statistics, Banaras Hindu University, Varanasi, Uttar Pradesh, India; ${ }^{4}$ Professor, Department of General Medicine, Institute of Medical Sciences, Banaras Hindu University, Varanasi, Uttar Pradesh, India; Junior Resident, Department of Community Medicine, Institute of Medical Sciences, Banaras Hindu University, Varanasi, Uttar Pradesh, India

\begin{tabular}{|c|c|c|c|c|c|c|c|c|}
\hline Abstract & Introduction & Methodology & Results & Conclusion & References & Citation & \multicolumn{2}{|c|}{ Tables / Figures } \\
\hline \multicolumn{9}{|c|}{ Corresponding Author } \\
\hline \multicolumn{8}{|c|}{$\begin{array}{l}\text { Dr. Madhutandra Sarkar, C-64 Swastik Towers, Lanka Main Road (BHU), Varanasi, Uttar Pradesh } \\
\text { 221005, India. } \\
\text { E Mail ID: } \underline{\text { dr.madhutandra.sarkar@gmail.com }}\end{array}$} & 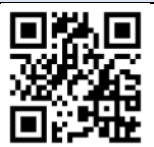 \\
\hline
\end{tabular}

\section{Citation}

Kansal S, Sarkar M, Kumar A, Chakravarty J, Kumar R. To Disclose or Not to Disclose? Reasons for HIV Serostatus Disclosure and Non-disclosure by People Living with HIV/AIDS in Eastern India. Indian J Comm Health. 2021;33(1):109-115. https://doi.org/10.47203/IJCH.2021.v33i01.015

Source of Funding: Nil Conflict of Interest: None declared

\section{Article Cycle}

Received: 27/01/2021; Revision: 13/02/2021; Accepted: 05/03/2021; Published: 31/03/2021

This work is licensed under a Creative Commons Attribution 4.0 International License.

\section{Abstract}

Background: Understanding the reasons for HIV serostatus disclosure and nondisclosure and how these reasons differ by certain characteristics of the people living with HIV/AIDS (PLWHA) is important for effective HIV prevention intervention strategies. Objectives: This study was undertaken to investigate/identify the reasons for disclosure and nondisclosure of HIV serostatus by PLWHA, and to find out any association between the reasons for disclosure or nondisclosure and certain demographic and clinical characteristics, i.e. age, gender, WHO clinical stage and CD4 count of the study population. Methods: A cross-sectional study was conducted among all patients of 18-49 years with confirmed HIV infection registered at the antiretroviral therapy (ART) center of a tertiary care hospital in eastern Uttar Pradesh, India for one year, from July 2017 to June 2018. Results: The most common reason for disclosure of HIV serostatus was the presence of any family member at the time of collection of HIV test report (68.5\%), and the most common reason for not disclosing the serostatus was stigmatization (68\%). The reasons for disclosure was found to be associated with the WHO clinical stage of the respondents $(p<0.05)$. Conclusions: The findings of this study highlights the need for tailoring intervention strategies for improving disclosure decision making according to the specific needs of PLWHA. There is also a need to address the concerns of those who are reluctant to disclose. More emphasis should be given on creating awareness about HIV stigma, on the importance of serostatus disclosure and secondary HIV prevention in the community.

\section{Keywords}

Serostatus; Disclosure; Non-disclosure; Reasons; People living with HIV/AIDS; India

\section{Introduction}

With a death toll of more than 35 million lives so far, HIV/AIDS continues to be one of the major global public health challenges.(1) Serostatus disclosure has become an important issue as the patients with HIV live longer due to effective treatment. Serostatus disclosure is a critical component of secondary HIV prevention with potential benefits for 
both the infected individual by increasing access to medical care and treatment services, improving adherence to antiretroviral therapy (ART) and better treatment outcomes, reducing high risk behavior and increasing opportunities for social support, and also society by reducing HIV transmission risk. $(2,3,4)$ HIV disclosure is also thought to contribute to reduced HIV stigma in the community and enhanced awareness of the importance of HIV prevention. $(5,6)$

While there are many advantages to and reasons for disclosing HIV status, there are also risks and reasons for deciding not to disclose. $(6,7)$ Most of these relate to the negative aspects that may potentially arise from disclosing HIV status. The negative effects of HIV serostatus disclosure may include rejection, assault, separation, divorce, stigma and discrimination. $(8,9)$

Entire eastern Uttar Pradesh is a highly sensitive zone for HIV infections because of its migrant and mobile populations. However, very few researches have been undertaken, especially on disclosure by people living with HIV/AIDS (PLWHA) to family, friends and social network members other than spouses or sexual partners, and how the reasons for disclosure or nondisclosure may differ by certain characteristics of PLWHA.

Understanding the reasons for disclosure or nondisclosure of HIV serostatus by PLWHA is important to plan effective intervention strategies that will help in secondary prevention of HIV and improve positive outcomes. This will lead to the achievement of the UNAIDS 90-90-90 treatment targets and in turn will help end the AIDS epidemic.(10)

\section{Aims \& Objectives}

1. To investigate/identify the reasons for disclosure and nondisclosure of HIV serostatus by PLWHA.

2. To find out any association between the reasons for disclosure or nondisclosure and certain demographic and clinical characteristics, i.e. age, gender, WHO clinical stage and CD4 count of the study population.

\section{Material \& Methods}

Type of Study: Hospital-based cross-sectional study. Place of Study: This study was conducted in the ART center of a tertiary care teaching hospital in Varanasi, Uttar Pradesh, India. This center is one of the ten centers of excellence in HIV care in the country and the only in Uttar Pradesh and Bihar where the facility for second and third line drugs is available. This center monitors the activity of 11 ART centers in Bihar, Uttar Pradesh and Madhya Pradesh. Link ART centers are located in the neighboring districts of Ballia, Ghazipur, Jaunpur, Mau, Sonebhadra, Bhadohi, Chandauli and Azamgarh. At the time of data collection, approximately 27000 patients were registered with this ART Center.

Duration of Study: One year, from July 2017 to June 2018.

Study Population: The study population consisted of all patients 18 to 49 years of age with confirmed HIV infection registered at the above-mentioned ART center. The patients were included in this study on their first attendance after completion of 6 months of ART. Patients who were severely ill were excluded. Sampling: The proportion of HIV serostatus disclosure to at least one member in the family was considered as the key variable in the sample size determination. Sample size was determined by using the formula: $n=\{p(1-p) \quad(z 2)\} / e 2$, where $p$ =proportion of HIV serostatus disclosure to at least one member in the family, $z=1.96$ ( $z$ value at 5 percent level of significance), e $=0.05$ (margin of error). Considering the proportion of HIV serostatus disclosure to at least one member in the family as $78 \%$ (based on the pilot study conducted on 35 patients), the sample size was calculated to be 264 . On adding $15 \%$ to account for contingencies such as non-response or recording error, the final sample size was found to be 303 .

Methodology: The number of days available for the data collection was 2 fixed days each week. Each day, around six patients were proposed to be selected for the interview during the 6-month period of data collection. The study participants were selected by random selection of the first patient and then every 3rd patient by using systematic random sampling technique. This process was continued until the required sample size was obtained.

The eligible patients were interviewed face to face using a pretested, semi-structured, questionnaire-cum-case record form in a separate room considering the privacy of the respondent. Individual patient record maintained on the white card was also analyzed to elicit clinical information. The questionnaire-cum-case record form consisted of the following sections, i.e., sociodemographic information, disclosure status, sexual risk behaviors before and after disclosure, and, lastly, immunological profile and WHO clinical staging. The 
first question that was asked in order to elicit the disclosure status of the patients was whether they had disclosed their HIV serostatus to any member of the family. This question was followed by whether they had disclosed their HIV serostatus to their sexual partners (spouses). The detailed methodology has been discussed elsewhere. (4)

Ethical Approval and Informed Consent: Ethical clearance for doing this study was obtained from the Institutional Ethics Committee. All the eligible patients were informed about the purpose of the study, and were assured regarding the confidentiality of the information obtained. Written informed consent for participating in the study was obtained from all of them.

Statistical Analysis: Statistical analysis was performed using the trial version of SPSS, version 22.0 (IBM Corp., Armonk, New York, United States).

\section{Results}

In this study, a total of 303 HIV/AIDS patients were initially interviewed. However, 288 patients were finally included in the analysis after excluding 15 cases due to inaccurate, unreliable information. Most of the respondents were aged $30-49$ years ( 230 or $79.9 \%$ ), male (182 or $63.2 \%$ ), married (246 or $85.4 \%$ ), rural residents ( 174 or $60.4 \%$ ), Hindu ( 278 or $96.5 \%)$, literate ( 242 or $84 \%$ ), employed/driver (178 or $61.8 \%)$, and belonged to lower/lower middle class (180 or $62.5 \%$ ) according to the modified BG Prasad scale (2018).(11) The HIV serostatus disclosure rate to at least one person in the family was found to be $82.6 \%(238 / 288)$, and most of them had disclosed to their spouses (221/238 or $92.9 \%)$.

(Table 1) shows that most $(68.5 \%)$ of the respondents who had disclosed, reported the reason for disclosure as the presence of any family member at the time of collection of HIV test report. The most common reason of not disclosing the HIV serostatus, as reported by the respondents who had not disclosed, was the fear of stigmatization (68\%).

As shown in (Table 2), the reasons for disclosure was not found to be associated with the age group, gender and CD4 count of the respondents ( $p>0.05)$. More than three-fourth (75.9\%) of the respondents in the $40-49$ years age group, and more than $60 \%$ of the respondents in the other two age groups, i.e. $30-$ 39 years $(65.1 \%)$ and $18-29$ years (younger age group) (63\%) had disclosed their HIV serostatus due to the presence of any family member at the time of collection of test report. It was also found that the most commonly stated reason for disclosure among both the male and female respondents was the presence of any family member at the time of collection of test report $(70.1 \%$ and $65.9 \%$ respectively). A statistically significant association was found between the reasons for disclosure and the WHO clinical stage of the respondents $(p<0.05)$. Higher proportion (84\%) of the respondents who had stage III-IV disease than their counterparts with the disease in stage I-II (about 63\%) had disclosed their serostatus due to the presence of any family member at the time of collection of test report. The proportion of the respondents in stage I-II of the disease (31.3\%), who had disclosed due to the need to get emotional, economical or treatment support, was almost double than the proportion of the respondents who had stage III-IV disease (14.5\%). This table also shows that about $70 \%$ of the respondents, who had CD4 count $\leq 350$ cells/mm3, had disclosed their status due to the presence of any family member at the time of collection of test report, whereas the same reason was stated by $63.5 \%$ of the respondents with CD4 count $>350$ cells $/ \mathrm{mm}^{3}$.

The reasons for non-disclosure was not found to be associated with the age group, gender, WHO clinical stage and CD4 count of the respondents ( $p>0.05$ ) (Table 3). It was observed that the fear of stigmatization was reported as the reason for nondisclosure by most of the respondents in all the age categories. Almost equal proportion of the male and female respondents ( $68.6 \%$ and $66.7 \%$ respectively) had reported the fear of stigmatization as the reason for non-disclosure. It was also observed from this table that nearly $70 \%$ (69.8\%) of the respondents in the WHO clinical stage I-II of the disease did not reveal their serostatus due to the fear of stigmatization, whereas lesser proportion (57.1\%) of the respondents with the disease in stage III-IV did not disclose due to the same reason. The proportion of the respondents with the CD4 count $\leq 350$ cells/mm3 who didn't disclose their serostatus due to the fear of stigmatization was higher than the proportion of the respondents with the CD4 count $>350$ cells $/ \mathrm{mm} 3$ ( $71.8 \%$ vs. $54.5 \%)$.

\section{Discussion}

This study is an attempt to investigate/identify the reasons for HIV positive serostatus disclosure as well as non-disclosure by PLWHA to any member of the family, and whether those reasons may differ 
depending on the certain demographic and clinical characteristics of the study population. In the present study, $82.6 \%(238 / 288)$ of the respondents had disclosed their HIV serostatus to at least one person in the family.

More than two-third (68.5\%) of the respondents who had disclosed their serostatus, did so due to the presence of any family member at the time of collection of test report. Other reasons for disclosure as reported were the need to get emotional, economical or treatment support from the family members (26.9\%) and the discovery of the ARV drugs at home by the family members (4.6\%). A study done in Uganda (12) had reported multiple reasons for disclosure including the need to get financial and social support $(35 \%)$, followed by the need to get treatment (33\%), and the desire that their partners also get tested (32\%). As per the report by Ssali et al.,(6) following a study done in Kampala, Uganda, the most common reasons for the disclosure were to receive support and to maintain the relationship ties (76\% each). Other reasons as reported were the compulsion to explain change in behavior or appearance (61\%) and the need for HIV prevention (50\%). The difference in the findings across different studies may be attributed to the differences in the population studied and sociocultural contexts of different regions.

In the present study, the most common reason for non-disclosure of HIV serostatus had been identified as the fear of stigmatization (68\%). Other reasons for non-disclosure had been found to be the fear of the respondents that their family members might get shocked (20\%) and the fear of discrimination (12\%). Almost similar to the present study, where $80 \%$ of the respondents who had not disclosed, did so due to the fear of stigmatization and discrimination, an Ethiopian study (13) had also reported the most common reason for non-disclosure as the fear of stigma and discrimination (84.5\%). Other reasons as reported in that study (13) were the fear of accusation of infidelity (79.6\%), fear of confidentiality $(74.0 \%)$ and fear of abandonment (10.2\%). The reasons for non-disclosure were found to be the fear of divorce (32\%), fear of stigma and discrimination (32\%), fear of physical abuse (16\%), fear of accusation of infidelity (12\%) and fear of confidentiality $(8 \%)$ in another study conducted in Northeast Ethiopia.(14) The different reasons for non-disclosure and the proportions of the respondents reporting those reasons may vary across different socio-cultural contexts, and stigma related to HIV/AIDS among the population across different settings.

The most common reason (63\% or more) for disclosure across all age groups, genders, clinical stages or CD4 levels was the presence of any family member at the time of collection of test report. Very few of the respondents had to disclose as the family members had seen the ARV drugs at home. Hovering around $30 \%$ (23-35\%) of the respondents across all age groups, genders and CD4 levels were compelled to disclose their serostatus to get emotional, economical or treatment support from the family members. The above findings reflect that most of the PLWHA in our socio-cultural context are reluctant to disclose their serostatus unless compelled, and there is a lack of awareness about the importance of serostatus disclosure, which are hindrances in getting increased support from the family or society.

In this study, the reasons for disclosure was associated with the WHO clinical stage of the respondents $(p<0.05)$. The proportion of the respondents in stage III-IV of the disease (83.9\%), who had reported the presence of any family member at the time of collection of test report as the reason for disclosure, was much higher than the proportion of the respondents with the disease in stage I-II (63.1\%), who had also cited the same reason for disclosure. The proportion of the respondents in stage I-II of the disease (31.3\%), who had disclosed for getting emotional, economical or treatment support, was more than double than the proportion of the respondents with the disease in stage III-IV (14.5\%), who had also disclosed due to the same reason.

In the present study, the reasons for non-disclosure was not associated with the age, gender, WHO clinical stage or CD4 level of the respondents. However, the fear of stigmatization was cited as the reason for non-disclosure by most of the respondents ( $54.5 \%$ or more) who had not disclosed, irrespective of all the age groups, genders, WHO clinical stages and CD4 levels.

\section{Conclusion}

The findings of this study highlights the need for tailoring intervention strategies to promote disclosure according to the specific needs of PLWHA. Moreover, there is a need to address the concerns of those who are reluctant to disclose. More emphasis 
should be given on creating awareness about HIV stigma, on the importance of serostatus disclosure and secondary HIV prevention in the community. Although the reasons for disclosure was not associated with the gender of the respondents in this study, given the socio-cultural context in India, gender-specific approaches to enhance HIV disclosure should be considered.

\section{Recommendation}

This study calls for empowering PLWHA with skills to make effective decisions. HIV-related stigma and discrimination can be a bottleneck to HIV testing and treatment. HIV/AIDS programs should be aimed at reducing stigma and discrimination in the community so as to promote a safer environment for disclosure. HIV prevention counselling in ART center must address issues of fear of disclosure and its subsequent negative consequences, including stigma and discrimination. The counsellors and other HIV service providers need to be trained on the identified factors which are hindrances or facilitators of serostatus disclosure. PLWHA also needs safe and supportive family to improve disclosure decision making and effectively promote secondary prevention of HIV.

\section{Limitation of the study}

This study has the following limitations. First, the sample studied may not be the representative of the whole population, as the study was conducted among the ART service users in a selected tertiary health care facility situated in eastern Uttar Pradesh. Pertaining to diversity in cultures and religions, sexual behavior may differ substantially across India. Second, the study was based on self-report of the respondents, and is therefore subject to reporting bias. Third, the possibility of social desirability bias cannot be totally eliminated as this study touched upon many sensitive issues. Last but not the least, the study was a quantitative one. It would have been better to incorporate qualitative research methods to gather more in-depth information on certain issues.

\section{Relevance of the study}

The findings of this study and thereby intervention measures as suggested based on the study findings can be helpful in secondary prevention of HIV. This may help achieve the UNAIDS 90-90-90 targets and in turn may help end the AIDS epidemic.

\section{Authors Contribution}

SK: Concept and study design, definition of intellectual content, editing and review of manuscript. She will act as guarantor of the manuscript. MS: Literature search, analysis and interpretation of data, preparation of manuscript, editing and review of manuscript. AK: Study design, statistical analysis, review of manuscript. JC: Concept, definition of intellectual content, review of manuscript. RK: Acquisition and analysis of data, review of manuscript.

\section{References}

1. World Health Organization. HIV/AIDS. Key Facts. Available from: https://www.who.int/news-room/factsheets/detail/hiv-aids. [Accessed Feb 06, 2021].

2. Shacham E, Small E, Onen N, Stamm K, Overton ET. Serostatus disclosure among adults with HIV in the era of HIV therapy. AIDS Patient Care STDS. 2012;26(1):2935. doi: 10.1089/apc.2011.0183. Epub 2011 Nov 22. PMID: 22107039; PMCID: PMC3279708.[PubMed].

3. Hallbergca D, Kimariob TD, Mtuyab C, Msuyab M, Björling G. Factors affecting HIV disclosure among partners in Morongo, Tanzania. Int J Afr Nurs Sci 2019; 10: 49-54.

4. Kumar R, Sarkar M, Kumar A, Chakravarty J, Kansal S. Factors affecting disclosure of HIV-positive serostatus among people living with HIV/AIDS attending an antiretroviral therapy center of Eastern India. Indian J Public Health. 2020;64(1):4-10. doi: 10.4103/ijph.IJPH_172_19. PMID: 32189675.[PubMed].

5. Paxton S. The paradox of public HIV disclosure. AIDS Care 2002;14: 559-567[PubMed].

6. Ssali SN, Atuyambe L, Tumwine C, Segujja E, Nekesa N, Nannungi A, Ryan G, Wagner G. Reasons for disclosure of HIV status by people living with HIV/AIDS and in HIV care in Uganda: an exploratory study. AIDS Patient Care STDS. 2010;24(10):675-81. doi: 10.1089/apc.2010.0062. PMID: 20863244; PMCID: PMC3826576.[PubMed].

7. Greeff $M$, Phetlhu R, Makoae LN, Dlamini PS, Holzemer WL, Naidoo JR, Kohi TW, Uys LR, Chirwa ML. Disclosure of HIV status: experiences and perceptions of persons living with HIV/AIDS and nurses involved in their care in Africa. Qual Health Res. 2008;18(3):311-24. doi: 10.1177/1049732307311118. PMID: 18235155.[PubMed].

8. Maman S, Mbwambo JK, Hogan NM, Weiss E, Kilonzo GP, Sweat MD. High rates and positive outcomes of HIVserostatus disclosure to sexual partners: reasons for cautious optimism from a voluntary counseling and testing clinic in Dar es Salaam, Tanzania. AIDS Behav. 2003;7(4):373-82. doi: 10.1023/b:aibe.0000004729.89102.d4. PMID: 14707534.[PubMed].

9. Ko NY, Lee HC, Hsu ST, Wang WL, Huang MC, Ko WC. Differences in HIV disclosure by modes of transmission in Taiwanese families. AIDS Care. 2007;19(6):791-8. doi: 
INDIAN JOURNAL OF COMMUNITY HEALTH / VOL 33 / ISSUE NO 01 / JAN- MAR 2021 10.1080/09540120601095718.

PMID:

17573600.[PubMed].

10. UNAIDS. 90-90-90 - An ambitious treatment target to help end the AIDS epidemic. Available from: https://www.unaids.org/en/resources/documents/201 7/90-90-90. [Accessed Feb 06, 2021].

11. Pandey VK, Aggarwal P, Kakkar R. Modified BG Prasad's socio-economic classification-2018: the need of an update in the present scenario. Indian J Comm Health 2018; 30: 82-84.

12. Kadowa I, Nuwaha F. Factors influencing disclosure of HIV positive status in Mityana district of Uganda. Afr
[HIV Serostatus...] | Kansal S et al Health Sci. 2009;9(1):26-33. PMID: 20842239; PMCID: PMC2932514.[PubMed].

13. Natae SF, Negawo MK. Factors affecting HIV positive status disclosure among people living with HIV in West Showa Zone, Oromia, Ethiopia; 2013. Abnorm Behav Psychol 2016; 2: 114.

14. Seid M, Wasie B, Admassu M. Disclosure of HIV positive result to a sexual partner among adult clinical service users in Kemissie district, northeast Ethiopia. Afr J Reprod Health. 2012;16(1):97-104. PMID: 22783673.[PubMed].

\section{Tables}

TABLE 1 DISTRIBUTION OF THE RESPONDENTS ACCORDING TO THE REASONS FOR HIV SEROSTATUS DISCLOSURE AND NON-DISCLOSURE TO ANY FAMILY MEMBER $(\mathbf{N}=\mathbf{2 8 8})$

\begin{tabular}{|l|l|}
\hline Reasons for disclosure or non-disclosure of HIV serostatus to any family member & $\begin{array}{l}\text { Number (\%) of the } \\
\text { respondents }\end{array}$ \\
\hline Reasons for disclosure $(n=238)$ & $163(68.5)$ \\
\hline Presence of family member at the time of collection of test report & $64(26.9)$ \\
\hline Need to get emotional, economical or treatment support from family members & $11(4.6)$ \\
\hline ARV drugs seen by family members at home & $34(68.0)$ \\
\hline Reasons for non-disclosure ( $n=50)$ & $10(20.0)$ \\
\hline Fear of stigmatization & $6(12.0)$ \\
\hline Fear that family members may get shock & \\
\hline Fear of discrimination & \\
\hline
\end{tabular}

\section{TABLE 2 ASSOCIATION BETWEEN THE REASONS FOR DISCLOSURE OF HIV SEROSTATUS WITH THE DEMOGRAPHIC AND CLINICAL CHARACTERISTICS OF THE RESPONDENTS ( $\mathbf{N}=\mathbf{2 3 8}$ )}

\begin{tabular}{|c|c|c|c|c|}
\hline \multirow{2}{*}{$\begin{array}{l}\text { Demographic and } \\
\text { clinical characteristics of } \\
\text { the respondents }\end{array}$} & \multicolumn{4}{|c|}{ Reasons for disclosure of HIV serostatus } \\
\hline & $\begin{array}{l}\text { Presence of family } \\
\text { member at the time of } \\
\text { collection of test } \\
\text { report }\end{array}$ & $\begin{array}{l}\text { Need to get emotional, } \\
\text { economical or treatment } \\
\text { support from family } \\
\text { members }\end{array}$ & $\begin{array}{l}\text { ARV drugs seen by } \\
\text { family members at } \\
\text { home }\end{array}$ & Total \\
\hline \multicolumn{5}{|l|}{ Age group (years) } \\
\hline $18-29$ & $29(63.0)$ & $14(30.4)$ & $3(6.5)$ & 46 \\
\hline $30-39$ & $71(65.1)$ & $31(28.4)$ & $7(6.4)$ & 109 \\
\hline $40-49$ & $63(75.9)$ & $19(22.9)$ & $1(1.2)$ & 83 \\
\hline Significance & \multicolumn{4}{|l|}{$\chi^{2}=5.404, d f=4, p=0.234$} \\
\hline \multicolumn{5}{|l|}{ Gender } \\
\hline Male & $103(70.1)$ & $40(27.2)$ & $4(2.7)$ & 147 \\
\hline Female & $60(65.9)$ & $24(26.4)$ & $7(7.7)$ & 91 \\
\hline Significance & \multicolumn{4}{|l|}{$\chi^{2}=3.160, d f=2, p=0.206$} \\
\hline \multicolumn{5}{|l|}{ WHO clinical stage } \\
\hline Stages I and II & $111(63.1)$ & $55(31.3)$ & $10(5.7)$ & 176 \\
\hline Stages III and IV & $52(83.9)$ & $9(14.5)$ & $1(1.6)$ & 62 \\
\hline Significance & \multicolumn{4}{|l|}{$\chi^{2}=9.310, d f=2, p=0.009$} \\
\hline \multicolumn{5}{|l|}{ CD4 count (cells $/ \mathrm{mm}^{3}$ ) } \\
\hline $\mathrm{CD} 4 \leq 350$ & $123(70.3)$ & $42(24.0)$ & $10(5.7)$ & 175 \\
\hline CD4 $>350$ & $40(63.5)$ & $22(34.9)$ & $1(1.6)$ & 63 \\
\hline Significance & \multicolumn{4}{|l|}{$\chi^{2}=4.074, d f=2, p=0.130$} \\
\hline
\end{tabular}


TABLE 3 ASSOCIATION BETWEEN THE REASONS FOR NON-DISCLOSURE OF HIV SEROSTATUS WITH THE DEMOGRAPHIC AND CLINICAL CHARACTERISTICS OF THE RESPONDENTS $(\mathbf{N}=50)$

\begin{tabular}{|c|c|c|c|c|}
\hline \multirow{2}{*}{$\begin{array}{l}\text { Demographic and clinical } \\
\text { characteristics of the } \\
\text { respondents }\end{array}$} & \multicolumn{4}{|c|}{ Reasons for non-disclosure of HIV serostatus } \\
\hline & $\begin{array}{c}\text { Fear of } \\
\text { stigmatization }\end{array}$ & $\begin{array}{c}\text { Fear that family } \\
\text { members may get } \\
\text { shock }\end{array}$ & $\begin{array}{c}\text { Fear of } \\
\text { discrimination }\end{array}$ & Total \\
\hline \multicolumn{5}{|l|}{ Age group (years) } \\
\hline $18-29$ & $11(84.6)$ & $1(7.7)$ & $1(7.7)$ & 13 \\
\hline $30-39$ & $14(66.7)$ & $4(19.0)$ & $3(14.3)$ & 21 \\
\hline $40-49$ & $9(56.3)$ & $5(31.3)$ & $2(12.5)$ & 16 \\
\hline Significance & \multicolumn{4}{|c|}{$\chi^{2^{*}}=3.049, d f=4, p=0.587$} \\
\hline \multicolumn{5}{|l|}{ Gender } \\
\hline Male & $24(68.6)$ & $8(22.9)$ & $3(8.6)$ & 35 \\
\hline Female & $10(66.7)$ & $2(13.3)$ & $3(20.0)$ & 15 \\
\hline Significance & \multicolumn{4}{|c|}{$\chi^{2^{*}}=1.633, d f=2, p=0.449$} \\
\hline \multicolumn{5}{|l|}{ WHO clinical stage } \\
\hline Stages I and II & $30(69.8)$ & $8(18.6)$ & $5(11.6)$ & 43 \\
\hline Stages III and IV & $4(57.1)$ & $2(28.6)$ & $1(14.3)$ & 7 \\
\hline Significance & \multicolumn{4}{|c|}{$\chi^{2^{*}}=1.003, d f=2, p=0.698$} \\
\hline \multicolumn{5}{|l|}{ CD4 count (cells $/ \mathrm{mm}^{3}$ ) } \\
\hline CD4 $\leq 350$ & $28(71.8)$ & $7(17.9)$ & $4(10.3)$ & 39 \\
\hline $\mathrm{CD} 4>350$ & $6(54.5)$ & $3(27.3)$ & $2(18.2)$ & 11 \\
\hline Significance & \multicolumn{4}{|c|}{$\chi^{2^{*}}=1.197, d f=2, p=0.511$} \\
\hline
\end{tabular}

